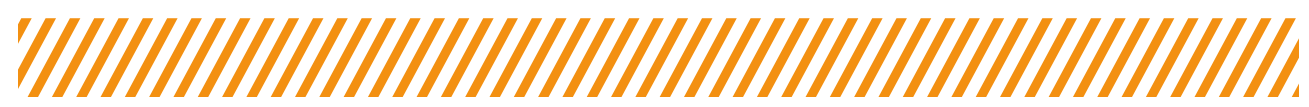

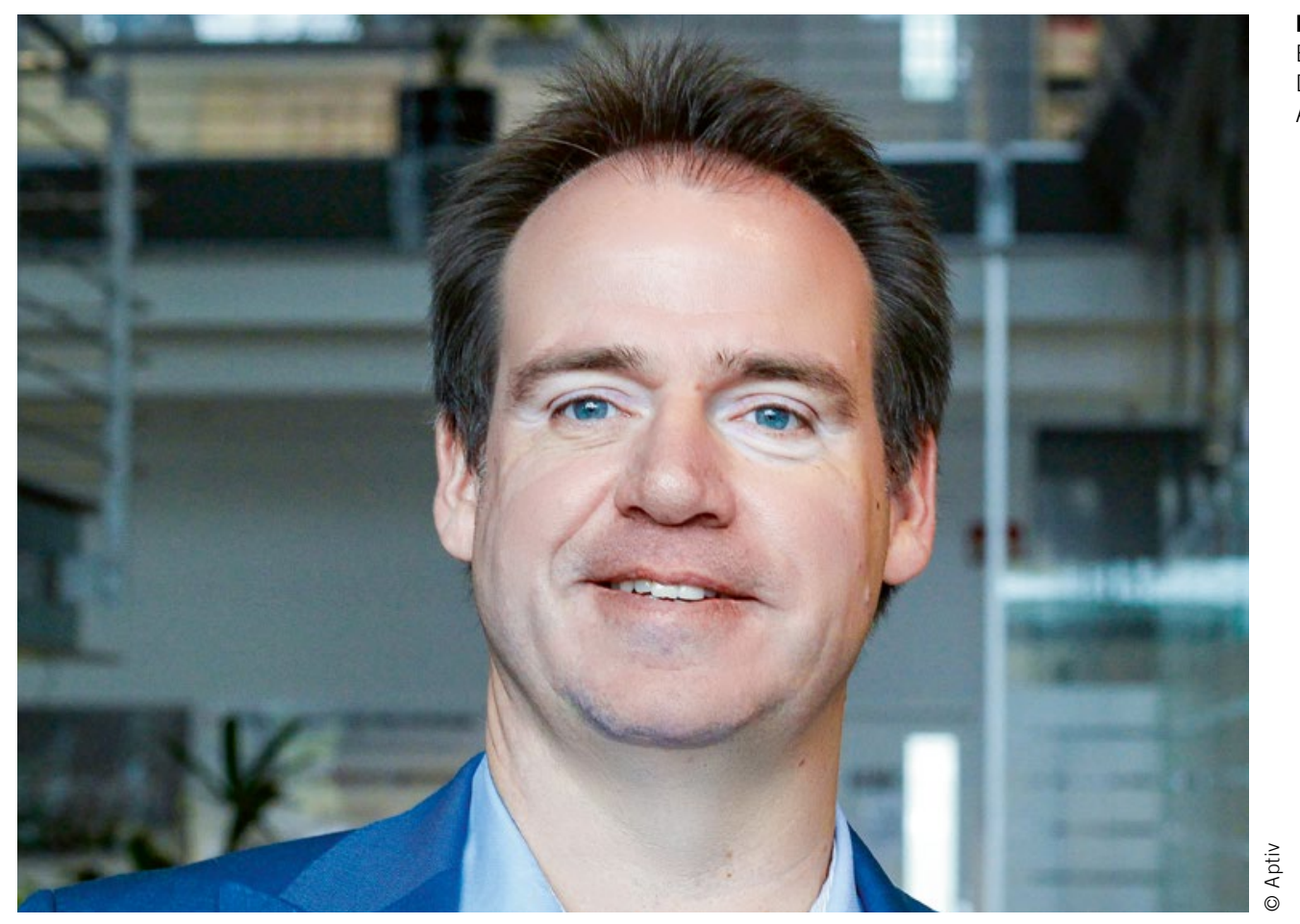

Dr. Karl-Heinz Glander

Europe Regional Engineering Director Advanced Safety bei Aptiv in Wuppertal

\section{Erhöhte Sicherheit mit kombinierter Innen- und Außensensorik}

Moderne Fahrerassistenzsysteme (ADAS) nutzen heutzutage die Fusion der Dateneingaben von zwei oder mehr Sensoren, um besser zu erkennen, was für Hindernisse sich um das Fahrzeug herum befinden. Eingaben von mehreren Sensoren werden verwendet, um zum Beispiel die jeweiligen Sichtfelder zu erweitern oder verschiedene Sensortechnologien zu kombinieren, um deren Vorteile optimal zu nutzen und Schwächen zu mildern.

In letzter Zeit beobachten wir das Aufkommen von Innensensoren, oft in Form einer Kamera, und sie können viele sicherheitsrelevante Feststellungen treffen, beispielsweise, ob der Fahrer den Blick auf die Straße richtet oder ob die Passagiere angeschnallt sind. Eine Kombination der Sensorinformationen über das, was außerhalb des Fahrzeugs geschieht, mit den Informationen über den Zustand des Fahrers im Fahrzeuginneren wird immer wichtiger. Durch die Fusion von Innenund Außensensordaten sind wir in der Lage, proaktiv vor einer gefährlichen Situation zu warnen, lange bevor ein Eingreifen erforderlich ist. Dies ist in Situationen hilfreich, in denen ein Fahrer schläfrig oder abgelenkt ist oder sich auf andere Aspekte der aktuellen Verkehrssituation konzentriert.

Nehmen wir als Beispiel ein Szenario, bei dem ein Fahrer an einer Kreuzung anhält und darauf wartet, nach rechts abzubie- gen. Er schaut kurz nach rechts und ab dann nach links, um auf eine Lücke im Verkehr zu achten, damit er schnell rechts abbiegen kann. In dieser Phase beginnt ein Fußgänger, vor ihm von rechts zu kreuzen. Der Innensensor sieht, wohin der Fahrer blickt, zusätzlich erkennt eines der Außenradargeräte den Fußgänger. Das System weiß, dass der Fahrer nicht hingeschaut hat, also warnt es ihn, dass die Person da ist - bevor es zu einem Unfall kommt. Gerade wenn Städte sich dazu entschließen, den Verkehrsraum immer dichter durch Fußgänger, Radund Scooterfahrer zusammen mit Autos zu nutzen, gewinnt diese vorausschauende Unterstützung immens an Bedeutung: Dank der Innensensorik registriert das Fahrzeug, wenn die Augen des Fahrers auf das Radio oder Navigationssystem statt auf die Straße gerichtet sind. Zugleich erfassen die Außensensoren, wie sich die Verkehrssituation ändert. Schneidet beispielsweise ein Fahrzeug die eigene Fahrspur und erzeugt eine Kollisionsgefahr, lösen die Systeme sehr früh eine Warnung aus, dass sich außerhalb des Fahrzeugs etwas abspielt, das Aufmerksamkeit erfordert. Visuelle und akustische Hinweise warnen den Fahrer, noch bevor ein klassisches ADAS überhaupt eingreifen würde: Das verhindert eine Notbremsung aufgrund eines späten Eingreifens und verbessert so das Sicherheitsniveau. 